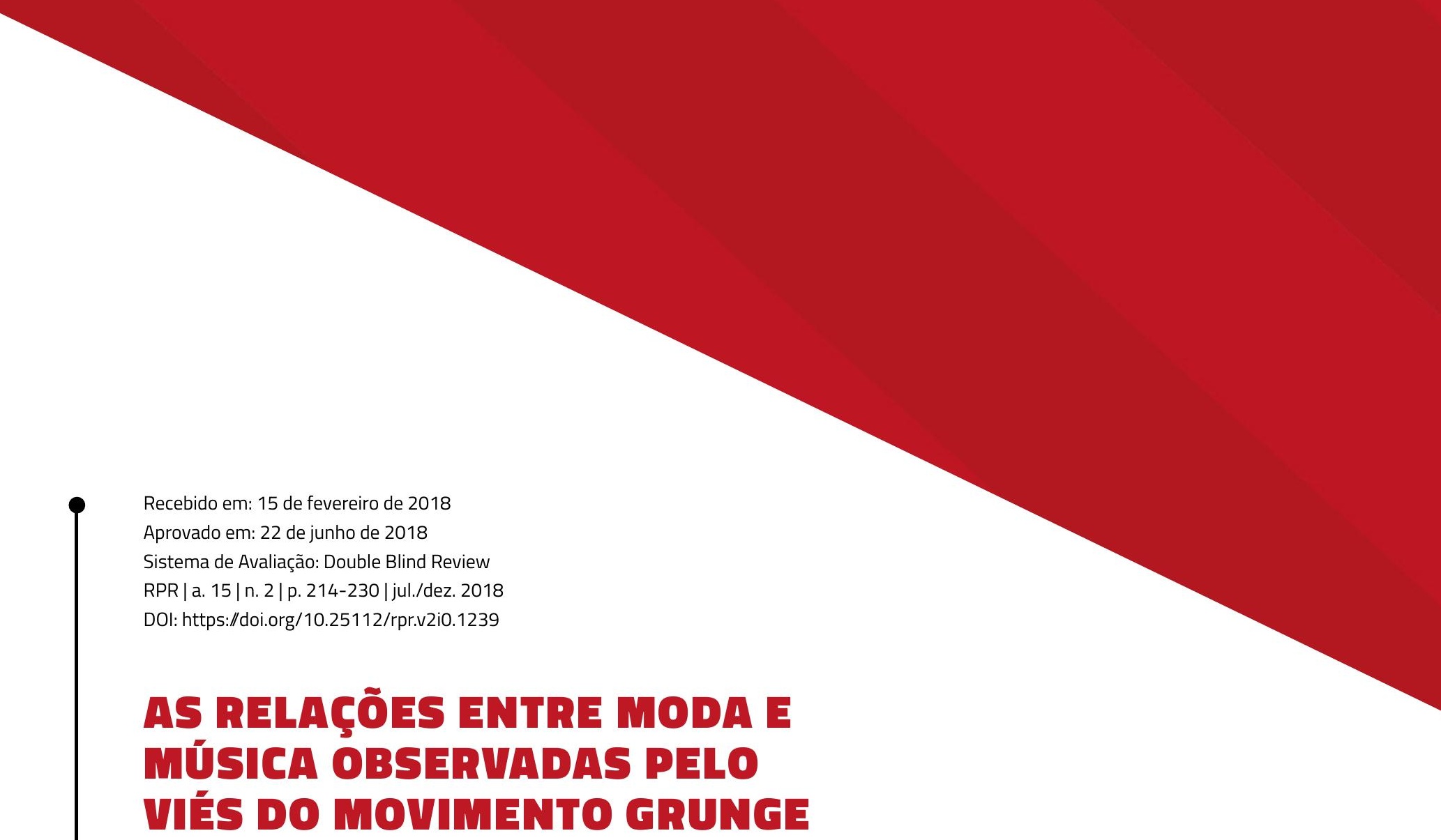

THE RELATIONSHIP BETWEEN

FASHION AND MUSIC OBSERVED BY THE BIAS OF THE GRUNGE MOVEMENT

\title{
Marianna Pires
}

Mestranda em Processos e Manifestações Culturais (Universidade Feevale/Brasil). E-mail: iboobebeeinfantil@gmail.com.

\section{Bruna Ruschel Moreira}

Doutora em Design (Universidade Federal do Rio Grande do Sul/Brasil).

Pesquisadora no Projeto ICD do Núcleo de Desenvolvimento de Produtos (NDP) da Universidade Federal do Rio Grande do Sul (Porto Alegre/Brasil).

E-mail: brunaruschel18@gmail.com. 


\section{RESUMO}

Este artigo objetiva a reflexão sobre possíveis relações entre moda e música, destacando o movimento musical grunge, surgido na década de 1990, em Seattle, de forma que busca identificar as possiveis influências na moda, por meio de vestimentas usadas pelos integrantes do movimento. Neste estudo, é destacada a banda Nirvana - significativa representante do movimento grunge - com o objetivo de comparar suas vestimentas com as coleções criadas por estilistas que se inspiraram na estética grunge no desenvolvimento de suas coleções. São analisados os trabalhos dos estilistas Marc Jacobs, Juliana Jabour, e Dries Van Noten, além do trabalho da marca britânica Marques' Almeida, nas décadas de 1990 e 2000. Assim, procurou-se evidenciar a teoria da ebulição, mencionada por Doris Treptow (2005), e verificar que estilos alternativos originários das ruas podem elevar-se na camada social, sendo trabalhados através do viés do luxo. Nesse sentido, entende-se a moda e a música como manifestações da cultura e enquanto formas de comunicação, de maneira que este artigo pretende contribuir com estudiosos de moda, música e áreas inter-relacionadas, considerando o caráter interdisciplinar da moda.

Palavras-chave: Moda. Música. Identidade. Grunge.

\section{ABSTRACT}

This article aims the reflection on possible relationships between fashion and music, highlighting the Grunge Musical Movement, emerged in the 1990s in Seattle, so that search to identificate possible influences on fashion, through the clothing worn by the members of the Movement. In this study, is highlighted the band Nirvana - a significant representative of the Grunge Movement - with the aim of comparing their clothes with collections created by stylists inspired by the Grunge aesthetics in their collections development. Thereby, it was tried to evident the Bubble-Up Theory, mentioned by Doris Treptow (2005), and check that alternative styles originating from the streets can elevate themselves in the social layer, being worked through the bias of the luxury. In this sense, fashion and music are understood as manifestations of culture and as forms of communication, that way this article intends to contribute with scholars of fashion, music and interrelated areas, considering the interdisciplinary character of fashion.

Keywords: Fashion. Music. Identity. Grunge. 


\section{INTRODUÇÃO}

Esse artigo tem como objetivo realizar a reflexão sobre as possíveis relações existentes entre a música e a moda. Nesse sentido, destaca-se o movimento musical grunge, surgido na década de 1990, em Seattle, região portuária ao noroeste dos Estados Unidos e fronteiriça com o Canadá. Trata-se de uma região gélida, chuvosa, com muitas fábricas e composta por uma cena cultural fraca, contexto ideal para o surgimento das bandas de "garagem", como eram denominados os grupos de rock alternativo.

Este trabalho está organizado da seguinte forma: primeiramente, a moda é abordada em seus aspectos históricos, por meio de uma breve contextualização, para, em seguida, abordar as suas possíveis relações com a música. Nesse sentido, procura-se analisar, de forma breve, de que maneira o movimento grunge se relacionou com a moda, além de evidenciar que o estilo se manteve ao longo do tempo, servindo de inspiração para que diferentes estilistas, cada um à sua maneira, fizessem uma releitura desse movimento que marcou relevantemente a cena musical da década de 1990.

Em um segundo momento, relacionando o movimento musical com a moda, são analisadas possíveis influências das bandas grunges nos hábitos de vestir, considerando que os grupos musicais não tinham a intenção de inspirar estilos, ao contrário, se apresentando totalmente despreocupados com o visual, interessando-se apenas pela música. No tocante a esse ponto, foi escolhido dar ênfase à banda Nirvana, considerada uma das maiores bandas grunges, sendo, portanto, uma representação significativa do movimento.

Sabe-se da despretensão das bandas em relação ao visual, porém, a moda enquanto manifestação da cultura, apropriou-se do estilo característico dos integrantes do movimento grunge e, em vista disso, alguns estilistas transformaram o estilo alternativo e originário das ruas em um produto luxuoso e sofisticado, elevando-o na escala social. Isso evidencia a teoria bubble-up, ou teoria da ebulição, mencionada por Doris Treptow (2005), a qual é abordada ao longo do trabalho na seção que relata o contexto da moda da década de 1990. A análise se dá através da comparação de imagens do antigo vocalista do Nirvana, Kurt Cobain, com as releituras de estilistas que trabalharam a estética grunge para desenvolverem suas coleções nas décadas de 1990 e 2000.

O primeiro estilista que se tem conhecimento, responsável pela apropriação do estilo grunge pela moda, foi o norte-americano Marc Jacobs. Em 1992, Jacobs desfilou uma coleção primavera/verão para a marca Perry Ellis, sintetizando o estilo grunge a partir dos seguintes elementos de estilo: camisa xadrez

\footnotetext{
${ }^{1}$ Rock alternativo é o nome dado para o som influenciado pelo punk rock, mas que não se encaixava em nenhuma vertente conhecida na época de seu surgimento (1980). Esse tipo de som adquiriu maior notoriedade na década de 1990.
} 
de flanela, calças folgadas, coturnos, toucas e camisetas de bandas pertencentes ao movimento. Ousado para a época, o estilista foi demitido, pois o desfile foi considerado de mau gosto para o público-alvo da marca. Porém, é possível observar que Jacobs se mostrava um estilista consciente dos acontecimentos do momento e, com o entendimento de que a moda é uma conexão com outras áreas, valorizou seu caráter interdisciplinar.

Ao longo das décadas, outros estilistas optaram por trabalhar a estética grunge, provando a permanência do estilo. Nesse artigo, são abordados os trabalhos mais recentes - dos anos 2000 - da estilista brasileira Juliana Jabour ${ }^{2}$, do estilista belga Dries Van Noten ${ }^{3}$ e da marca britânica Marques' Almeida ${ }^{4}$. Tais estilistas foram selecionados para a análise em virtude de terem feito suas releituras do grunge por meio do viés do luxo, trabalhando os elementos originais de forma sofisticada, porém, sem perder a sua essência, ou seja, mantendo elementos de estilo que foram consagrados como pertencentes ao movimento grunge.

\section{MODA E MÚSICA: SEUS ASPECTOS SOCIAIS E SUAS POSSÍVEIS RELAÇÕES}

O conceito de moda surgiu no final da Idade Média e início da Renascença (século XV), na Corte de Borgonha, atual parte da França, paralelamente com o desenvolvimento das cidades e o crescimento do comércio burguês. Enriquecidos, os burgueses começaram a imitar as roupas usadas pelos nobres, pois, apesar de não pertencerem à nobreza, passaram a ter condições de se vestirem como tal e, assim, iniciou-se o ciclo da moda: os nobres criavam e os burgueses imitavam.

Segundo Palomino (2003), nesse período, porém, ainda não havia o conceito de costureiro ou estilista. Complementando, Moutinho (2000) afirma que o primeiro estilista foi Charles Frederick Worth (18251895), ao criar, em Paris, uma maison ${ }^{5}$ e apresentar seus modelos em formato de desfiles com manequins.

Assim, o conceito de costureiro data do século XIX, período em que surgem cada vez mais profissionais da área, fazendo roupas sob medida em suas maisons. Foi apenas no final do século XIX e início do século XX - especificamente após a Segunda Guerra Mundial (1939-1945) - que surgiu o prêt-à-porter ${ }^{6}$, em decorrência da escassez de recursos que ocorria no período e, consequentemente, a perda de poder em adquirir uma roupa feita sob medida, considerada artigo de luxo.

\footnotetext{
${ }^{2}$ Estilista brasileira, que costuma trabalhar muito com malharia, priorizando o conforto.

${ }^{3}$ Estilista belga elogiado, conhecido pela mistura de estampas e materiais em suas coleções.

${ }^{4}$ Marca britânica dos portugueses Marta Marques e Paulo Almeida. Costumam trabalhar com uma moda mais despojada.

${ }^{5}$ Termo em francês que significa "casa", usado também para descrever estabelecimentos comerciais de prestígio.

${ }^{6} \mathrm{O}$ termo em francês significa "roupa pronta para usar".
} 
Segundo Moutinho (2000), é no século XX que ocorrem as grandes mudanças, pois a moda deixa de ser vista como atividade frivola e "as pessoas se convencem de que ela está ligada às modificações que atingem a sociedade em vários aspectos" (MOUTINHO, 2000, p. 10).

Nessa linha, Palomino (2003, p. 14) esclarece que a moda é "um sistema que acompanha o vestuário e o tempo, que integra o simples uso das roupas no dia a dia a um contexto maior, político, social, sociológico". Ainda nesse contexto, segundo Jones (2005), a moda é uma forma de ornamentação do corpo, mas, atualmente, o seu foco e o seu uso estão relacionados a uma forma de manifestação de inquietações sociais e mudanças culturais, concluindo que "as políticas de identidade estão estreitamente associadas com as roupas que escolhemos" (JONES, 2005, p. 24).

A respeito desse caráter social da moda, Jones (2005, p. 34) explica que, ao estudar a sua história, percebe-se que por meio de costumes de diferentes países, "todas as sociedades, das mais primitivas às mais sofisticadas, usam roupas e ornamentos para transmitir informações sociais e pessoais". A mesma autora ainda complementa que, assim como os sujeitos tentam ler expressões faciais das pessoas ao seu redor, também é possível ler os sinais que são emitidos através de suas roupas: "essa comunicação não verbal - a linguagem da moda -, pode ser aprendida como qualquer outra linguagem" (JONES, 2005, p. 34).

Dessa forma, pode-se entender a moda como parte de um contexto social, que vai além da função de proteção ao corpo, atuando como uma forma de comunicação. E assim como a moda, a música também pode ser considerada uma forma de manifestação cultural, estando relacionada a marcas de identidade.

A música ajuda a demarcar "territórios culturais", identificando grupos e formas de vida. Trabalhando com adolescentes, por exemplo, pode-se observar a quantidade de rotulações que eles dão à música, como "música de criança", "música de velho", "música de amor", "música de gay", "música de igreja", "música de dançar", "música para dormir", entre tantas outras (BEINEKE apud CÂNDIDO, 2004, p. 61).

Nesse sentido, é possível observar que a música pode ser um meio de construção de identidade, pois, como ressaltado, parece existir um rótulo para cada personalidade: a "música de igreja" identifica o devoto; a "música de dançar" identifica o dançarino; a "música de amor" identifica o apaixonado, etc.

Assim, a música, estando relacionada às linguagens e formas culturais diversas, se conecta com a moda através de vestimentas específicas, pois, ao mesmo tempo em que se pode dizer que existe a "música do roqueiro", essa música que identifica o admirador de rock está relacionada a um conjunto de elementos, tais como adornos, tatuagens, maquiagens, tipos de cabelo e, também, roupas que vão identificar esse roqueiro. 
Portanto, a música e a moda se relacionam para, juntas, através de um conjunto de recursos estéticos, exercerem a função de comunicar algo - uma ideia ou um manifesto, por exemplo - estando relacionadas a marcas de identidade e fazendo parte de um cenário social.

\section{UM BREVE CONTEXTO DA MODA DA DÉCADA DE 1990}

A alta costura que entra em decadência no fim dos anos 1980, motivada por uma crise financeira, cede lugar às roupas prêt-à-porter que, conforme Baudot (2005), faz com que algumas maisons fechem suas portas ou se transformem em grandes marcas para sobreviver. Nesse contexto de crise, as marcas também optam por atender em diversas frentes, ampliando sua gama de produtos e explorando novos nichos de mercado. Dessa forma, o prêt-à-porter é definitivamente a "onda" do momento, com suas inovações tecnológicas facilitando a produção em série, mantendo a boa qualidade e proporcionando preços mais acessíveis ao consumidor final.

Quanto aos estilos adotados na década de 1990, Moutinho (2000) explica que a moda se mostra cada vez mais plural, caracterizando a vestimenta ocidental como uma multiplicidade de tendências que permite conviver os estilos dos últimos lançamentos com a moda retrồ, postulando o fim da ditadura de estilos. Nesse cenário plural, tem-se em evidência a presença das tribos urbanas, com seus variados estilos, como os clubbers ${ }^{8}$, punks ${ }^{9}$ e grunges, este último estilo como objeto do presente artigo.

Quanto às tribos urbanas, tem-se observado o fenômeno do bubble-up ou teoria da ebulição que, conforme estudos de Doris Treptow (2005), são estilos que surgem, primeiramente, nas ruas e, após, elevam-se no topo da escala social. Segundo a autora, um grupo desenvolve um estilo de vestir específico, a moda se apropria desse estilo, dando um nome e divulgando-o em meios de comunicação, após, formadores de opinião o adotam e, por último, surgem versões sofisticadas no mercado de luxo e nas passarelas (TREPTOW, 2005, p. 28).

Este é o caso do movimento grunge, nascido nas ruas através de bandas de rock alternativo, as chamadas bandas de garagem - que na verdade não tinham intenção de ditar moda - e elevou-se na camada social por meio do trabalho de estilistas, tornando-se até mesmo um produto de luxo, como é visto no decorrer do artigo.

\footnotetext{
${ }^{7}$ Diz-se da moda inspirada em décadas passadas.

8 Termo em inglês atribuído à tribo de pessoas que frequentavam danceterias (os clubs), ouviam música eletrônica e tinham um estilo característico de se vestir, com roupas coloridas, compondo um visual chamativo. Foi uma tribo muito comum nos anos 1990.

9 Tribo urbana adepta da subcultura/movimento punk, que foi um movimento social juvenil, surgido na década de 1970. Os simpatizantes do punk adotavam um visual de estética agressiva, como roupas rasgadas, rebites, correntes, entre outros elementos de estilo.
} 


\section{MOVIMENTO GRUNGE E O SEU MAIOR REPRESENTANTE: A BANDA NIRVANA}

Quando se ouve falar em movimento grunge, que, aliás, é uma variação de grungy(sujo), frequentemente a banda Nirvana vem à mente das pessoas que conhecem minimamente sobre o rock da década de 1990. Isso se deve ao fato da banda ser uma das mais relevantes ou, até mesmo, a maior representante do movimento.

Segundo Vinil (2008), o movimento grunge foi o movimento que mais marcou o início da década de 1990, com um estilo criado a partir de influências do rock de Detroit, no final da década de 1960, e do heavy metal ${ }^{10}$, do Black Sabbath ${ }^{11}$, no início da carreira, sendo o grunge, portanto, uma mistura do heavy metal e do punk.

A banda Nirvana era formada por Kurt Cobain, no vocal e na guitarra, pelo baixista Krist Novoselic e por Dave Grohl, na bateria. É evidente que o vocalista Kurt teve grande notoriedade, por ser o líder da banda e o compositor principal. Nesse sentido, Kurt contou parte de sua vida nas suas músicas, como afirma Orozco (2002, p. 8):

Em sua música, Kurt soltava raiva quando sentia raiva; era doce quando se sentia doce; despachava rancores e pedia desculpas quando magoava alguém; tinha tristeza e humor. Imperfeito, complexo, vivo. E transparente, mesmo quando os versos pareciam enigmas sem sentido para outras pessoas.

Quanto às letras das músicas, estas eram, na sua maioria, agressivas e densas, traduzindo aspectos de sua vida pessoal, visto que Kurt tinha uma vida problemática e envolvimento com drogas.

Mas, segundo Orozco (2002), por mais movimentada e turbulenta que tenha sido a vida de Kurt, foi sua música que o transformou em uma figura de destaque: "[Kurt] Cobain não alcançaria ninguém se não soubesse fazer uma canção direta, excitante e simples", e a banda não teria sucesso "sem a competência e o senso de dinâmica de Krist Novoselic e Dave Grohl na bateria" (OROZCO, 2002, p. 8).

O sucesso da banda, porém, não foi suficiente para manter Kurt vivo, que se suicidou em abril de 1994. Com isso, decretou-se o fim do Nirvana, porém, provando o sucesso da banda, álbuns póstumos foram lançados e uma legião de jovens, mesmo tendo passado muitos anos de seu término, ainda usam camisetas da banda, mostrando sua admiração, e evidenciando as relações possiveis entre a música e os modos de vestir.

\footnotetext{
${ }^{10}$ Subgênero do rock, que se desenvolveu no fim da década de 1960 e início da década de 1970, que tem como característica guitarras distorcidas e efeitos sonoros amplificados por meios eletrônicos.

${ }^{11}$ Banda de heavy metal britânica, surgida no final da década de 1970.
} 


\section{AS RELAÇÕES ENTRE MODA E MÚSICA}

Conforme visto anteriormente, as bandas do movimento grunge não tinham a intenção de ditar moda, preocupando-se apenas com a música. Fica evidente o seu descaso com o visual, visto que suas roupas não seguiam o padrão estético da época, possuindo um caráter alternativo e underground ${ }^{12}$.

Porém, a moda, como um meio de difusão de ideias, se apropriou do estilo grunge, que é composto por calças jeans rasgadas, modelagens largas, sobreposições de peças, camisetas de bandas, tricôs e roupas de frio - como a camisa de flanela xadrez -, expressando a teoria bubble-up, já apresentada nesse trabalho.

Nesse sentido, o primeiro estilista que se tem conhecimento, que se apropriou da estética do movimento, é o norte-americano Marc Jacobs, que trabalhava para a marca Perry Ellis, conforme já mencionado. Em 1992, na coleção de primavera/verão, Jacobs traduziu o estilo das ruas para as passarelas: modelagens largas; uso de padronagens diversas, como listras, florais e o famoso xadrez da camisa de flanela; toucas de lã e coturnos. Completando o estilo, as modelos usavam cabelo desarrumado e pouca maquiagem, sugerindo o estilo informal do grunge.

No quadro número 1, tem-se uma imagem de Kurt Cobain, vocalista do Nirvana, e a releitura de Marc Jacobs: mistura de estampas, sobreposições de peças - blusa, calça corsário ${ }^{13}$, vestido e camisa amarrada na cintura -, coturnos, cabelo desarrumado e touca, representando o visual despojado dos adeptos do Movimento.

\footnotetext{
${ }^{12}$ Expressão usada para designar um ambiente cultural que foge dos padrões comerciais e dos modismos.

${ }^{13}$ Calça cujo comprimento é um pouco abaixo do joelho.
} 


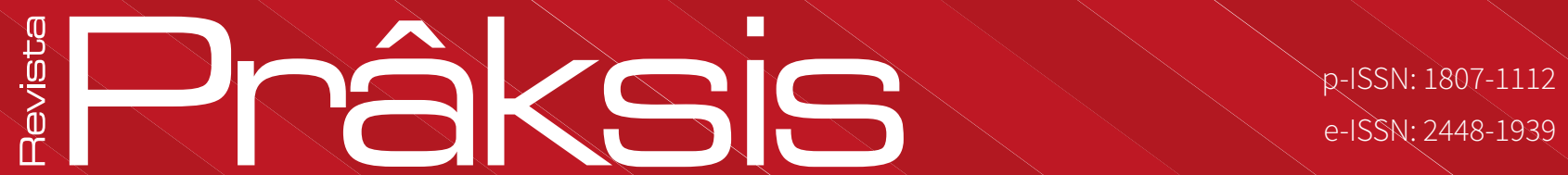

Quadro 1 - De um lado, Kurt Cobain, do outro, a tradução do Grunge de Marc Jacobs
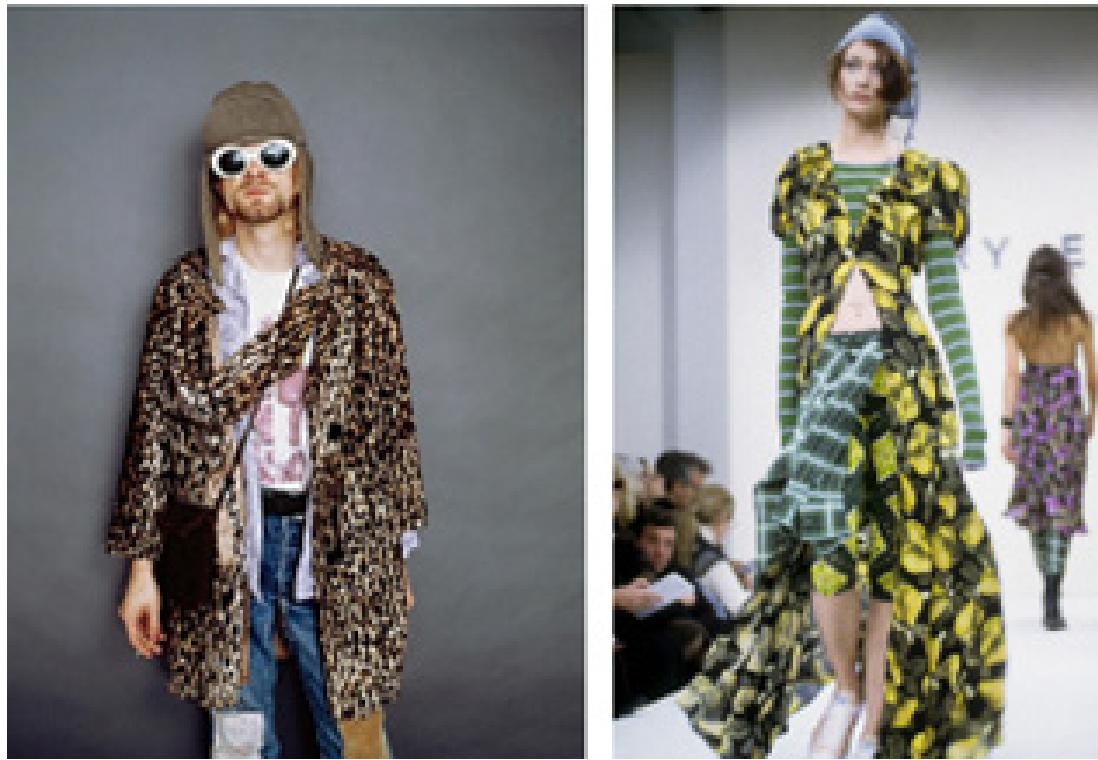

Fonte: Elaborado pela autora ${ }^{14}$

Já no quadro número 2, observa-se novamente a imagem de Kurt, vestindo uma camisa xadrez - um ícone grunge -, e a versão de Jacobs para a Perry Ellis, que apresentou uma versão mais sofisticada da camisa, numa composição com blazer e tecidos que, aparentemente, parecem ser nobres.

14 Disponivel em: <http://www.vogue.com/fashion-shows/spring-1993-ready-to-wear/perry-ellis/slideshow/collection\#53>. Acesso em: 20 abr. 2017.; Disponível em: <http://images4.fanpop. com/image/photos/21800000/Kurt-Cobain-kurt-cobain-21805204-393-500.jpg>. Acesso em: 20 abr. 2017. 


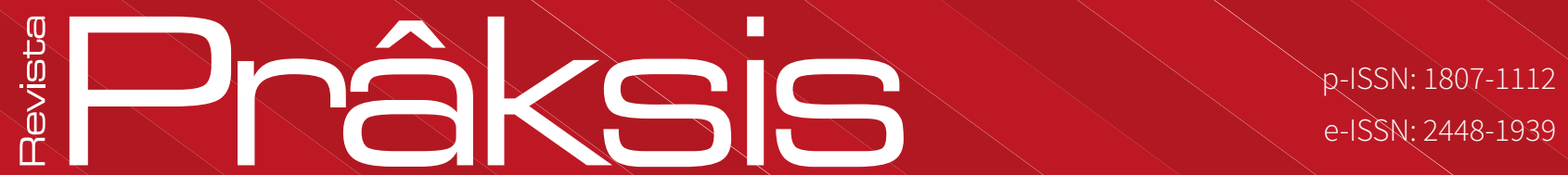

Quadro 2 - Camisa de flanela xadrez, um ícone do Movimento Grunge
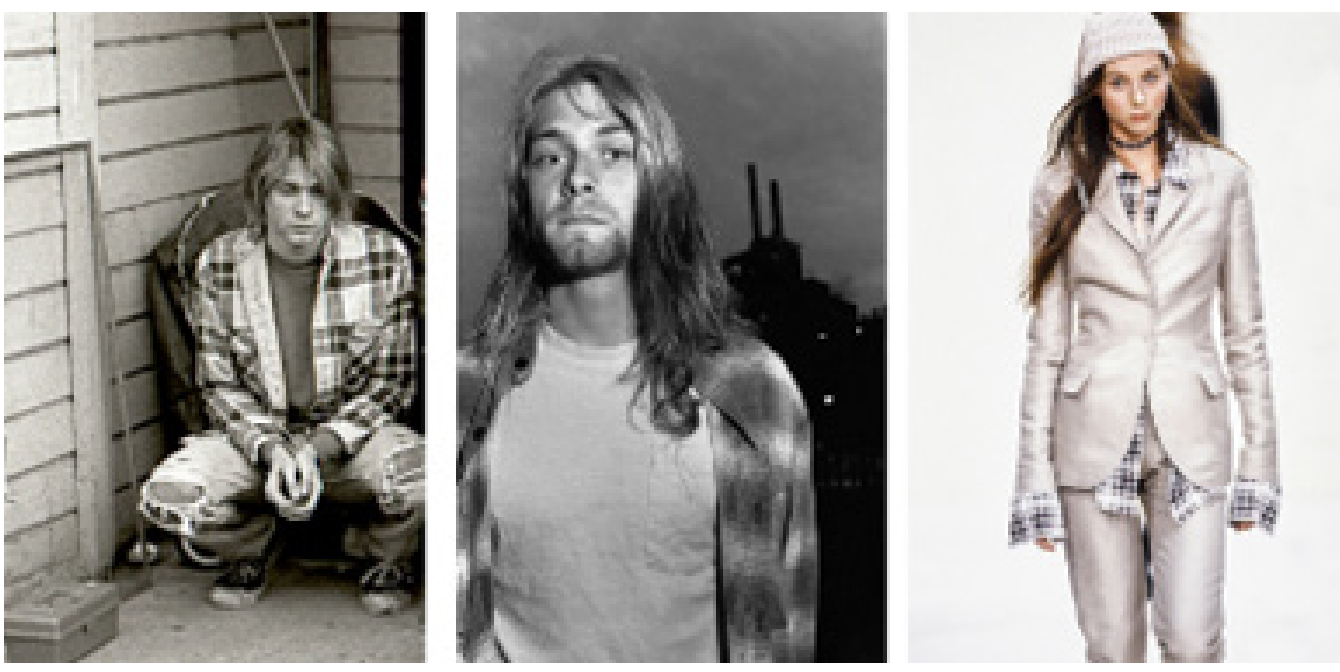

Fonte: Elaborado pela autora. ${ }^{15}$

Ao se realizar uma análise do estilo grunge de Marc Jacobs, pode-se dizer que o estilista trabalhou de forma bastante apropriada, transformando elementos originários da "rua" para um público consumidor de moda.

Porém, tal desfile ocasionou a demissão do estilista, pois foi julgado como um discurso de mau gosto para o público ao qual a marca se destinava. Em contrapartida, a revista Vogue ${ }^{16}$, concedeu ao estilista um editorial intitulado Grungy and glory (Grunge e glória), fotografado por Steven Meisel para a Vogue Itália, em dezembro de 1992.

No editorial, como se percebe no quadro número 3, as modelos estão vestindo roupas de modelagens largas, camisas de flanela, peças sobrepostas umas às outras, ou amarradas na cintura, assim como também há uma mistura de estampas em uma mesma composição. Ainda usam toucas de tricô e coturnos.

Ao se analisar as imagens, entende-se que a peça de maior destaque é a camisa da banda Nirvana, e acredita-se que, desse modo, parece ser evidente que a música influencia a moda através das vestimentas.

\footnotetext{
15 Disponivel em: <http://thehypebr.com/2013/11/11/kurt-cobain-homens-de-estilo/<< Acesso em: 20/04/2017. Disponível em: <https://s-media-cache-ak0.pinimg.com/originals/71/2a/4a/712a4aef6c30f5820ee2f2117a0683d1.jpg>. Acesso em: 20 abr. 2017. Disponivel em: <http://www.vogue.com/fashion-shows/spring-1993-ready-to-wear/perry-ellis/slideshow/collection\#3>. Acesso em: 20 abr. 2017.

${ }^{16}$ Vogue é uma das principais publicações de moda.
} 


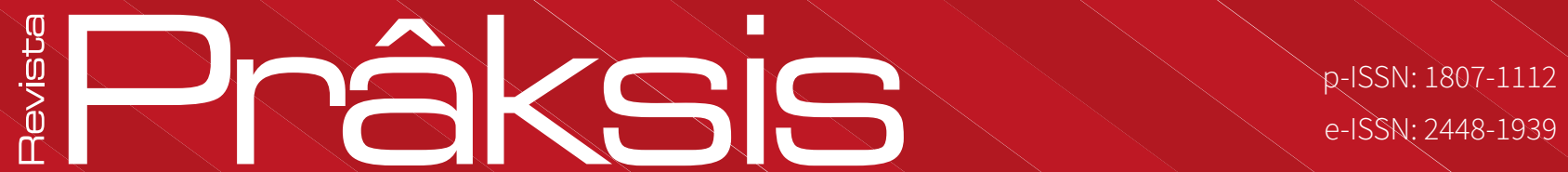

Quadro 3 - Editorial Grunge and Glory, para Vogue Itália, em dezembro de 1992

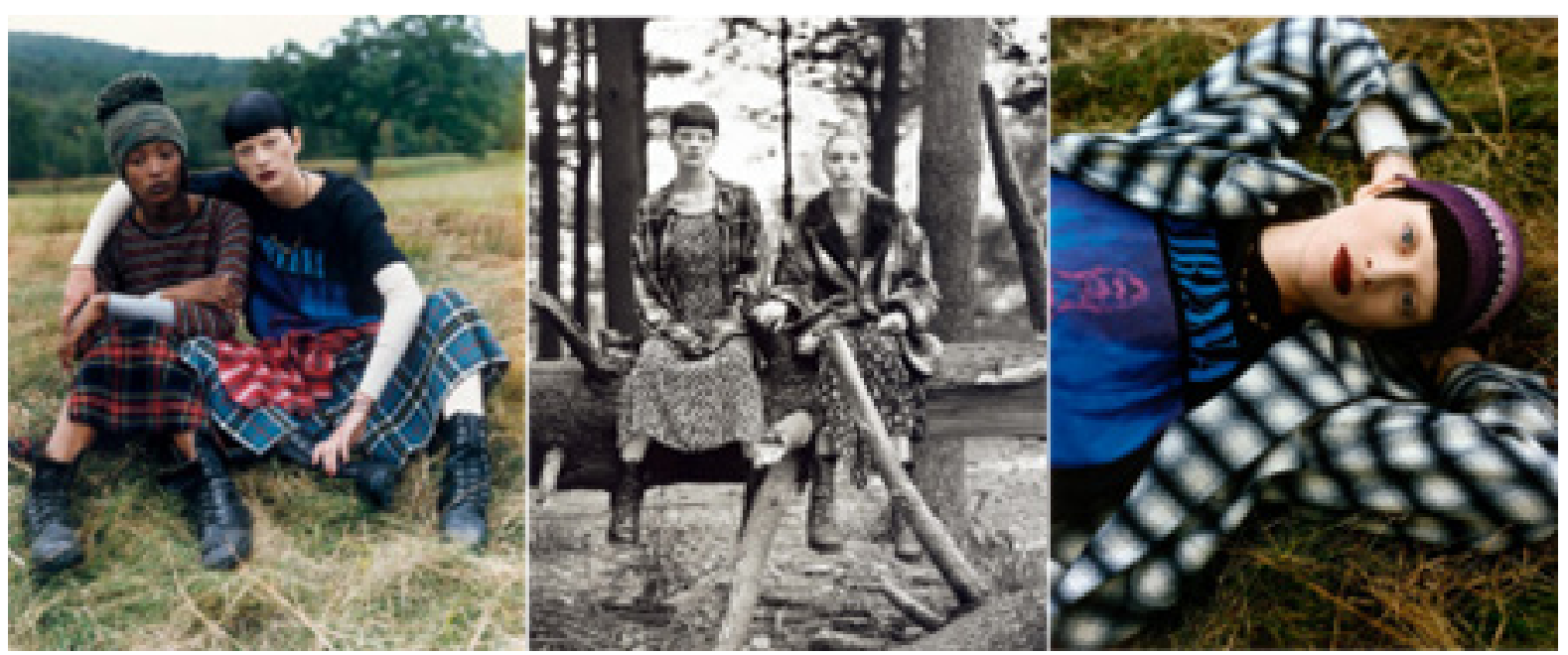

Fonte: Elaborado pela autora ${ }^{17}$

Mais recentemente, pode-se observar que o estilo grunge é revisitado nas coleções de moda de diferentes estilistas. Juliana Jabour, estilista brasileira, se inspirou na estética grunge para desenvolver a sua coleção inverno 2011, trabalhando os elementos característicos do movimento, de forma contemporânea.

Observa-se no quadro número 4, na imagem à esquerda, que a estilista faz uso do que pode ser considerado como o grande ícone grunge: a camisa de flanela xadrez. A camisa é sobreposta a uma camiseta, acompanhada de uma saia longa de modelagem solta e com aspecto brilhoso, além de coturnos.

Nota-se, no mesmo quadro, na imagem à direita, que Juliana Jabour aborda a temática de forma sofisticada, optando por tecidos como o tafetá e aplicações de bordados feitos com aviamentos cintilantes, que remetem à lantejoulas ${ }^{18}$, formando o desenho de grafismos. Tais elementos resultam em uma estética diferente do grunge original, porém, com muitos elementos que mantêm a essência do estilo, como a estampa xadrez, já mencionada, as silhuetas levemente amplas, as cores neutras, e a

\footnotetext{
17 Disponível em: <http://www.vogue.com/13293785/marc-jacobs-perry-ellis-grunge-collection-90s-fashion/>. Acesso em: 20 set. 2016.; Disponivel em: <http://steven-meisel.tumblr.com/post/506791850/vogue-us-dec-1992-grunge-and-glory-by-steven>. Acesso em: 20 set. 2016.; Disponivel em: <http://witchbriar.blogspot.com.br/2011/09/time-for-some-grunge.html>. Acesso em: 20 set. 2016.

${ }^{18}$ Lantejoulas são pequenas lâminas cintilantes, compostas por seis lados que lhes conferem relevo, além de um orifício para passagem de linha. São utilizadas para bordar e seu uso é comum em roupas de festa.
} 


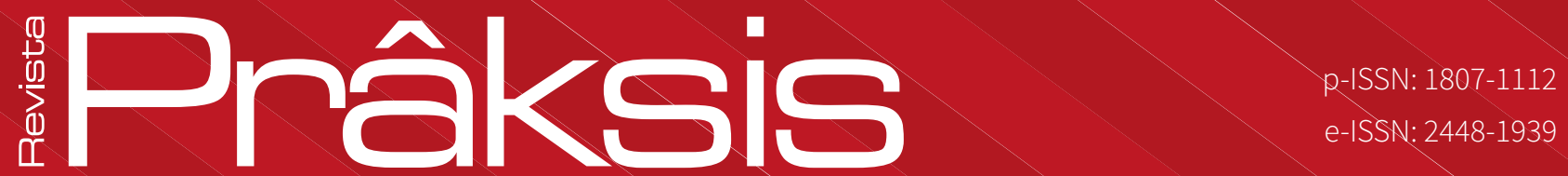

escolha de coturnos.

Percebe-se, também, que a mesma figura é similar ao visual proposto por Marc Jacobs, para a Perry Ellis, em 1992 (ver quadro número 1). Em termos de modelagem, ambas as propostas são de modelagens mais soltas. Em termos estéticos, as amarrações na cintura se repetem. Também é possível perceber, em ambas as imagens, o jogo de estampas: em Jacobs, é possível observar quatro estampas diferentes, já Juliana Jabour mistura xadrez com grafismos.

\section{Quadro 4 - Grunge revisitado por Juliana Jabour, inverno 2011}
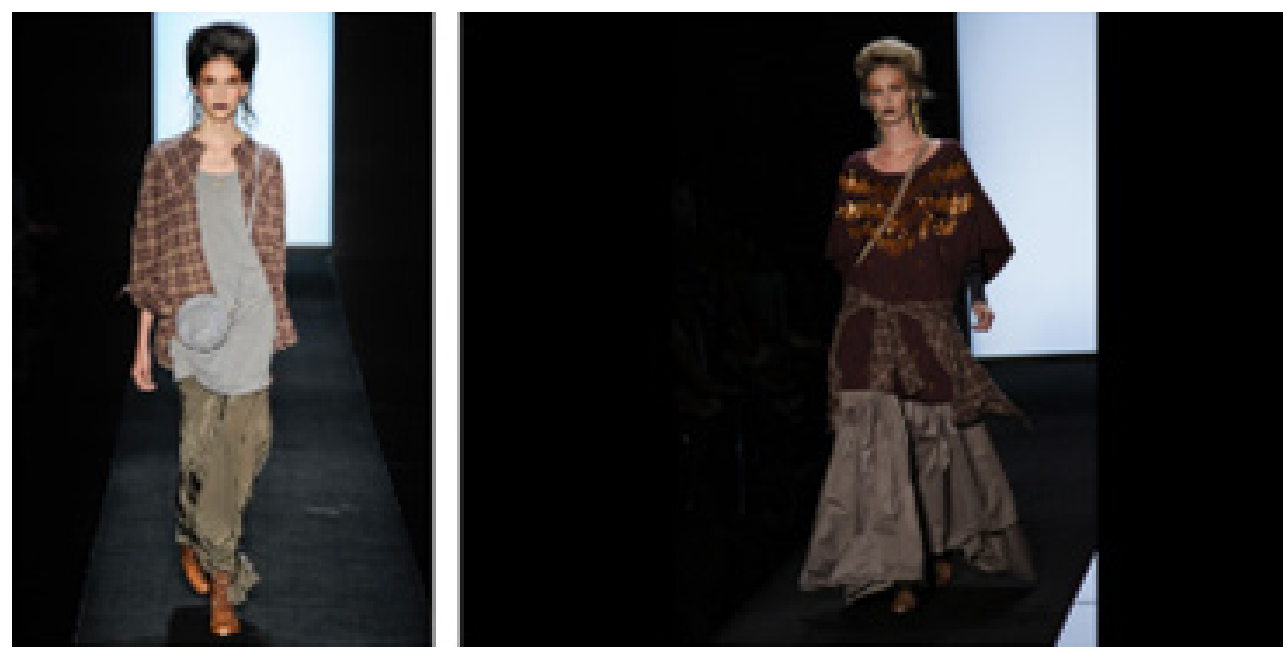

Fonte: Elaborado pela autora ${ }^{19}$

Seguindo a linha do grunge sofisticado, tem-se a marca belga Dries Van Noten, de estilista de mesmo nome. Como se observa no quadro número 5, o estilista trabalhou na sua coleção primavera/verão 2013 com tecidos finos e transparentes, como sedas e organzas, além de tecidos acetinados e trabalhados em texturas, trazendo, ainda, para sua coleção, a estampa xadrez e as sobreposições como os elementos do grunge.

\footnotetext{
${ }_{19}$ Disponível em: <http://blogfashiondanana.blogspot.com.br/2011/01/desfile-juliana-jabour.html>. Acesso em: 20 abr. 2017 .;
} Disponivel em: <http://blogfashiondanana.blogspot.com.br/2011/01/desfile-juliana-jabour.html>. Acesso em: 20 abr. 2017. 


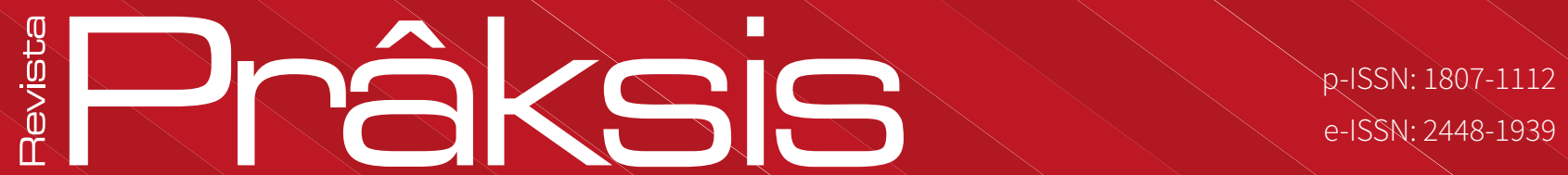

Quadro 5 - A marca belga Dries Van Noten e o seu Grunge sofisticado
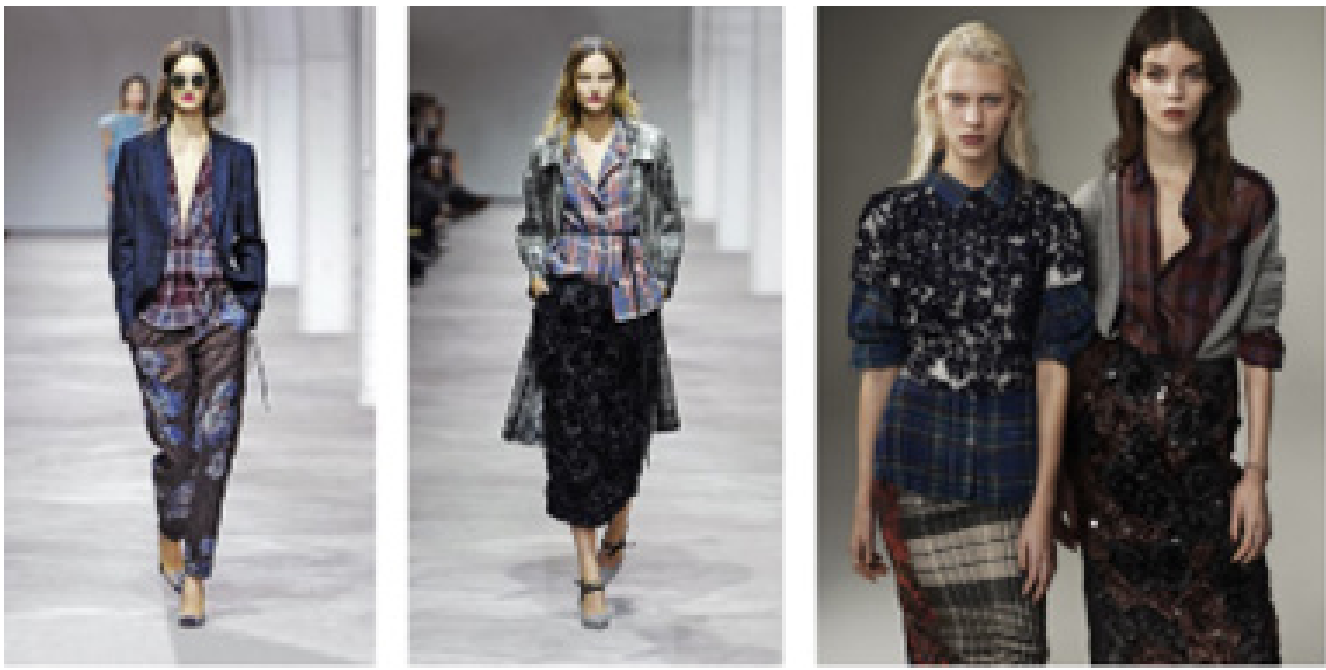

Fonte: Elaborado pela autora ${ }^{20}$

A marca britânica, Marques' Almeida, dos estilistas portugueses Marta Marques e Paulo Almeida, optou pelo tema grunge em duas coleções recentes: no outono/inverno 2013/2014 e na primavera/ verão 2015.

Na primeira coleção, como nota-se no quadro número 6, a marca utiliza jeans, seja rasgado ou estampado, material que também foi adotado por integrantes do movimento. Os estilistas "brincam" com a estética grunge propondo calças com comprimentos exagerados, que se arrastam ao chão e camiseta ampla, fazendo uso também das sobreposições - outra marca grunge. Para completar, as modelos usam cabelos desalinhados.

20 Disponível em: <http://fotos.caras.uol.com.br/media/images/large/2012/12/05/img-459783-moda-ready-wear-spring-2013-dries-van-noten.jpg>. Acesso em: 20 abr. 2017.; Disponivel em: <http://fotos.caras.uol.com.br/media/images/large/2012/12/05/img-459781-moda-ready-wear->. Acesso em: 20 abr. 2017. 


\section{Quadro 6 - Muito jeans no Grunge de Marques' Almeida - inverno 2013}

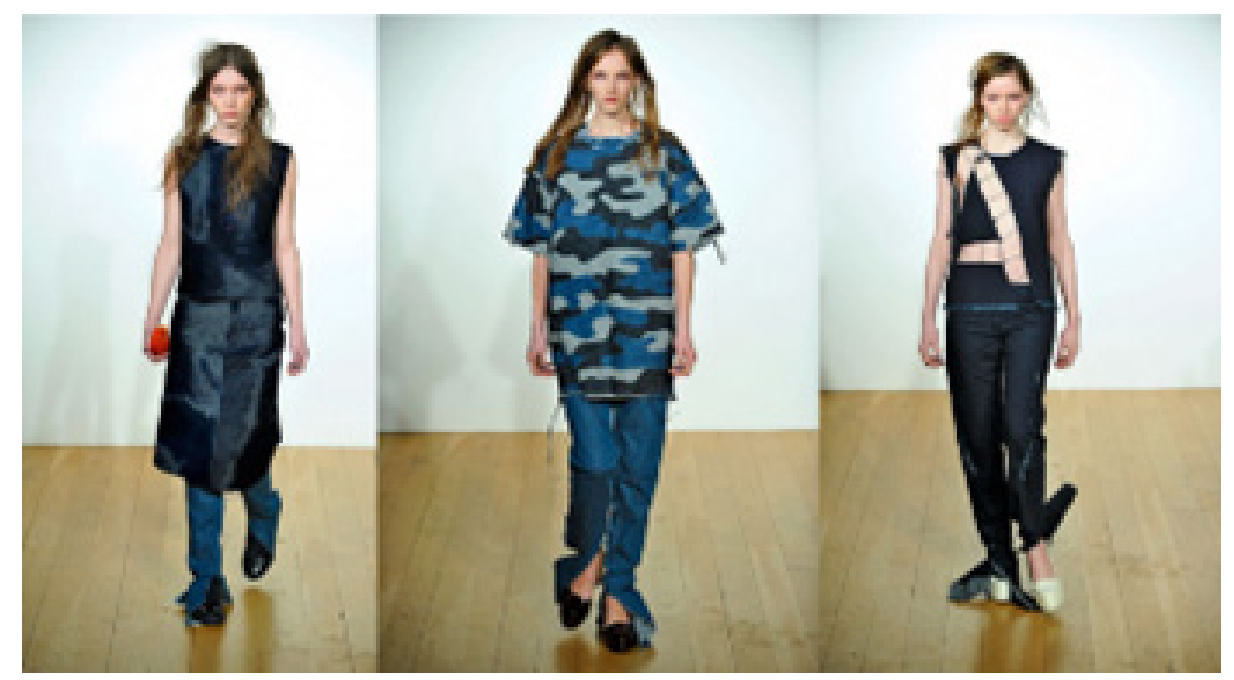

Fonte: Elaborado pela autora ${ }^{21}$

Já no quadro número 7, tem-se imagens da coleção primavera/verão 2015, onde os estilistas revisitaram o grunge com leveza e sofisticação, através de tecidos finos e transparentes que parecem chiffon ou seda, utilizando ora a cor preta, ora toques de cores mais vibrantes, no uso de aplicações de pedrarias. Já as modelagens assimétricas e os cabelos desarrumados das modelos dão os indícios da temática escolhida.

\footnotetext{
${ }^{21}$ Disponível em: <http://www.lilianpacce.com.br/desfile/marques-almeida-outono-inverno-201314/>. Acesso em: 20 abr. 2017.
} 


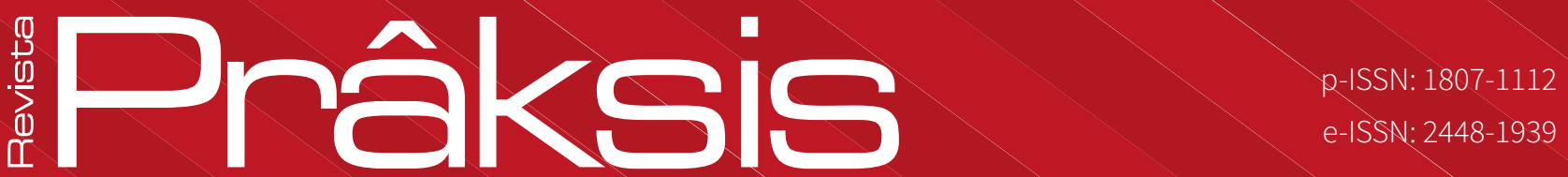

Quadro 7 - Leveza e transparência na coleção Marques' Almeida - verão 2015

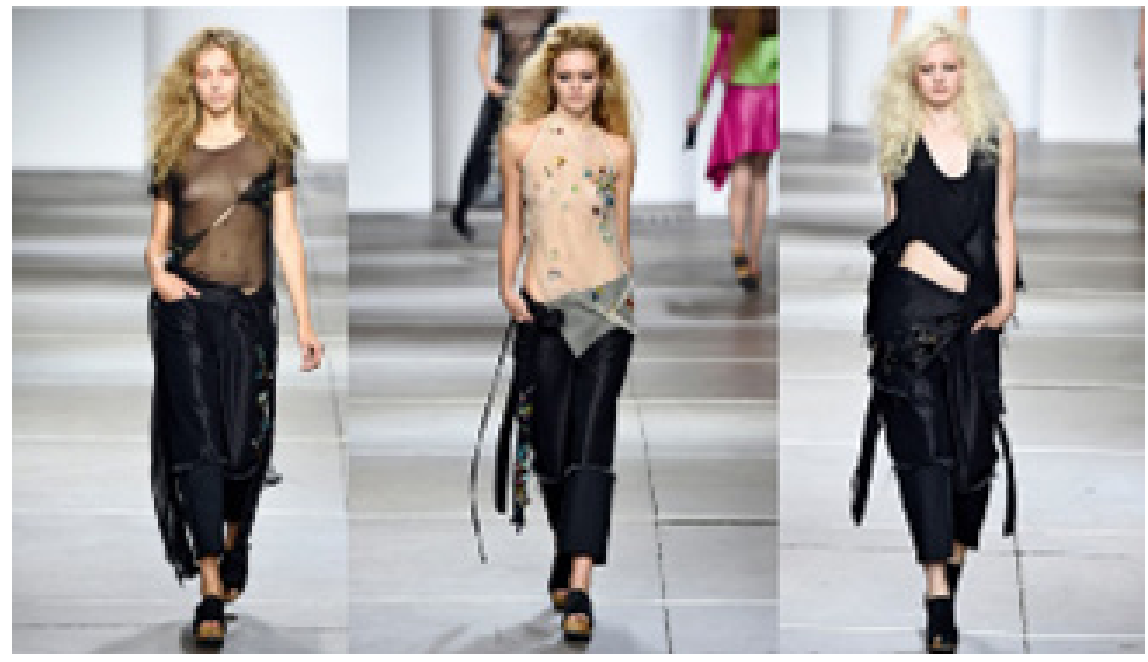

Fonte: Elaborado pela autora ${ }^{22}$

Analisando essas marcas, acredita-se que o movimento grunge influenciou maneiras de vestir e, como visto anteriormente nesse estudo, observa-se aqui a teoria bubble-up, visto que as marcas apresentadas optaram por trabalhar os elementos grunges pelo viés do luxo, contribuindo, assim, para elevar na camada social um estilo originário das ruas.

Dessa forma, o estilo alternativo do grunge adquiriu destaque no cenário da moda, proporcionando que um grande público tomasse conhecimento dessa estética característica, assim como foi possível demonstrar que a moda se relaciona com outras áreas - nesse caso, a música - evidenciando o caráter interdisciplinar da mesma.

\section{CONSIDERAÇÕES FINAIS}

Ao longo desse artigo, procurou-se mostrar que a música e a moda se relacionam, quando a música tem relevante competência para exercer influências sobre a moda, através das vestimentas.

Primeiramente, considerou-se importante conceituar moda e música, em seus aspectos sociais e enquanto formas de manifestações culturais - mesmo que de maneira breve - assim como contextualizar a moda da década de 1990, período do apogeu das bandas do movimento grunge.

22 Disponível em: <http://www.lilianpacce.com.br/desfile/marques-almeida-primavera-verao-2015/>. Acesso em: 20 abr. 2017. 
Nessa mesma linha, considerou-se importante apresentar a banda de maior destaque na cena grunge - o Nirvana -, para, então, relacionar o movimento com a moda e suas possíveis influências nos hábitos de vestir. Isso se deu através da apresentação de imagens onde se buscou analisar as releituras dos estilistas escolhidos e, desse modo, fazer uma comparação com as vestimentas de Kurt Cobain, o vocalista do Nirvana.

Assim, mostrou-se o trabalho de estilistas que se inspiraram nas bandas grunges, como o pioneiro Marc Jacobs, que se inspirou no estilo em 1992, para desenvolver a coleção primavera/verão da Perry Ellis. E mais recentemente, a estilista brasileira Juliana Jabour, o estilista belga Drie Van Noten e a marca britânica Marques' Almeida, dos estilistas portugueses Marta Marques e Paulo Almeida, que trabalharam a estética grunge nos anos 2000, provando que o estilo se manteve ao longo das décadas.

Nota-se que os estilistas e marcas apresentados fizeram releituras do estilo característico das bandas grunges, com adaptações no que se refere aos materiais, mantendo, porém, a essência do estilo original. Nesse sentido, se torna possivel perceber que o estilo grunge foi trabalhado por estes estilistas através do viés do luxo, ou seja, eles transformaram o estilo originário das bandas de rock alternativo em peças sofisticadas ao optarem pela utilização de tecidos finos, como sedas, organzas, tafetás, malhas com aspecto brilhoso, tecidos texturizados ou ainda aplicações de pedrarias e aviamentos cintilantes. Tais escolhas de materiais e a forma como os estilistas se inspiraram no grunge evidenciam a teoria da ebulição, como mencionado anteriormente nesse artigo.

Retornando aos estudos de Cândido (2004), que relaciona a música às diferentes linguagens, dentre elas, a linguagem da moda, pode-se concluir que a música tem uma estreita relação com a moda, uma vez que as vestimentas atuam como formas de comunicação e marcas de identidade, indo além de sua função de proteção ao corpo, sendo, inclusive, um importante meio de manifestação cultural.

\section{REFERÊNCIAS}

BAUDOT, François. Moda do século. 3. ed. São Paulo, SP: Cosac Naify, 2005, 399 p.

CÂNDIDO, Celir Barela. Por que música? In: GOBBI Valeria (Org.) et al. Questões de música. Passo Fundo: UPF, 2004, $185 \mathrm{p}$.

JONES, Sue Jenkyn. Fashion Design: manual do estilista. São Paulo, SP: Cosac Naify, 2005, 240 p. 


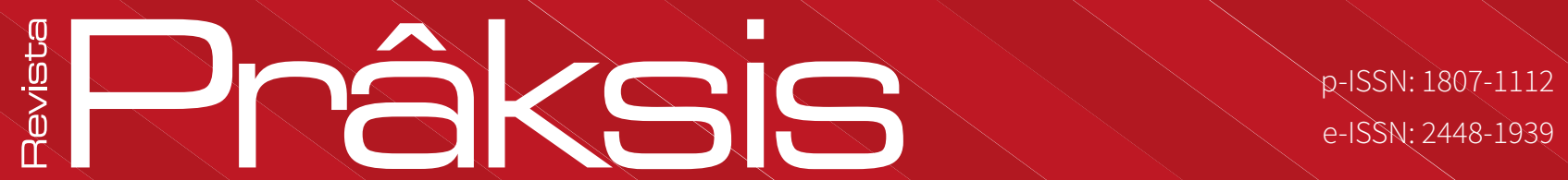

MOUTINHO, Maria Rita. Moda no século XX. Rio de Janeiro, RJ: Senac Nacional, 2000, 317 p.

OROZCO, Marcelo. Kurt Cobain: fragmentos de uma autobiografia. São Paulo: Conrad, 2002, 223 p.

PALOMINO, Erika. A Moda. 1. ed. São Paulo, SP: Publifolha, 2003,.

TREPTOW, Doris. Inventando moda: planejamento de coleção. 3. ed. Brusque: Ed. Do Autor, 2005, 209 p.

VINIL, Kid. Almanaque do rock. São Paulo, SP: Ediouro, 2008. 